\title{
Study of Reverse Logistics in the E-commerce Environment
}

\author{
Jian Xu \\ School of management \\ Shenyang University of Technology \\ No.111, Shen Liao Road (western) \\ Shenyang Economic Technological Development Zone \\ Shenyang 110178, China, \\ E-mail: jiangyuehxg@126.com \\ Yue Jiang \\ School of management \\ Shenyang University of Technology \\ No.111,Shen Liao Road(western) \\ Shenyang Economic Technological Development Zone \\ Shenyang 110178, China \\ E-mail: jyhxg@yahoo.com.cn
}

\begin{abstract}
Application of electronic commerce promotes logistics development.With the market completion enhancing, corporations need decrease their costs and increase consummers' satisfaction. These problems make the reverse logistics' value exposed in modern logistics. From the classification and characteristic of the reverse logistic, this paper analyzes the reasons and the problems in the development of the reverse logistic, also gives out some symmetries on how to solove these problems.All this can make the reverse logistics in the electronic commerce develop.
\end{abstract}

Keywords: Electronic commerce, Reverse logistics, Develop

\section{Introduction}

With the rapid popularization of the Internet, the burgeoning of e-commerce, it brings a profound change for economy and society, the circulation closely related to is no exception. E-commerce and logistics are the complement to each other, logistics is the fundamental guarantee for e-commerce, and e-commerce is the future for the logistics, both tend to intergrate with the development of information technology. In recent years, the rapid development of e-commerce, breaks the boundaries of regional and national,then opens up a vast market of online business, modern logistics have a huge space for development. At the same time, e-commerce transactions can not be the object of experience, the buyer can only get commodities information from pictures, that often exists a certain degree deviation, so in recent years, the returned volume of e-commerce increases sharply. The lack of good return channels is the main reason for the customers to give up on-line transactions. Many well-known foreign companies take reverse logistics strategy as a important too to reduce costs, increase customer satisfaction and strength the advantage of competitive. As a result, e-commerce development can not leave the support of reverse logistics, and the efficient operation of the reverse logistics also need e-commerce.

\section{Connotations and characteristics of reverse logistics}

\subsection{Connotation of reverse logistics}

Reverse Logistics Executive Committee defined reverse logistics as: plan, implement and control the raw materials, semi-finished goods inventory, the finished goods and the related information, efficiently and economicly control the process flow from the consumption point to the start, in order to achieve the value for recycling and disposaling properly. Reverse Logistics include return reverse logistics and recovery reverse logistics. 


\subsection{Features of reverse Logistics}

(1) Slow

The slow of reverse logistics is mainly reflected in the slow pace of accumulation on the amount of reverse logistics, the complexity of the dealing process, the slow recovery of recovery value.

(2) More beginning points.

The biggest difference between logistics and reverse logistics is that the different number of starting point and ending point. In the forward logistics, the products often move from a starting point to many destinations. On the contrary in the reverse logistics, products move from many starting points to one destination.

(3) Poor predictability.

In the forward Logistics, the business only need to predict the future market demand, each of the operating segments are based on market forecast, and the whole process is highly predictable. And reverse logistics is based on the reaction, it's usually not the plan or the result of the decision-making, but it's the reaction of consumers. Reverse logistics starts by the final individual consumer, and individuals in deciding return or not will be affected by many factors, so companies can not know how many products will return and the state of recovery. This has resulted in reverse logistics has greater uncertainty, is also more difficult to predict.

\section{The reasons of reverse logistics development in e-commerce environment}

\subsection{Laws and regulations}

In order to protect the environment and promote recycling of resources, at the same time in order to standardize the Web site and the protection of the right of consumers, many countries have legislation expressly provides that e-commerce sites must take Return Policy.

\subsection{The driven of competition}

E-commerce have changed the business environment, With the large-scale e-commerce applications, return rate of transaction online has reached $36 \%$. In today's market-oriented economic environment, customers' value is the key factor for the survival and development of business. So now more and more enterprises recognize the importance of the reverse logistics, in order to improve the customer satisfaction and enhance competitive advantage

\subsection{Asymmetric Information}

In the e-commerce model, customers often can only see the electronic images or electronic statement of the reference goods. From the visual perception of goods, customers can not fully understand the characteristics of the purchased goods, at the same time, the false information of goods has also increased the possibility of misleading. A large number of reverse logistics will generate When the goods received is different from the one seen in the Internet.

\section{Problems of reverse logistics development in e-commerce environment}

there are many same points between Reverse Logistics and the Forward Logistics, and also have the composition and logistics functions of Forward Logistics, that is: packaging, handling, transporting, storage, processing and other functions, but also its own characteristics. these characteristics make reverse logistics have enormous challenge.

\subsection{Internal neglect.}

Reverse Logistics has become an important part of management strategy in many foreign countries. In recent years, although many companies set up special recycling departments and reverse logistics recycling system, but we should clearly see that many companies excluded the reverse logistics from the activities of business strategy. No modern concept of reverse logistics, reverse logistics in the "foil" or "subsidiary" status, a significant number of enterprises see the reverse logistics as the burden, see its expenses as the cost of additional business.

\subsection{The higher complexity system}

In the reverse logistics system, there is a high degree of uncertainty on the time and quantity in recovery process of the consumer or end-market, at the same time the Internal logistics of reverse logistics system reflect each other, this leading to reverse logistics system is lack of effective control, thereby the complexity of the system is increasing .In addition, enterprises can not predict how many products will recovery and can not predict the condition of recovery, coupled with the high costs of delaying, so it is difficult for us to use many already existing e-commerce applications, forecast technology and mathematical model in supply management.

\subsection{The lack of experience in reverse logistics}

Reverse Logistics in China has just started in the stage, especially in e-business environment, our logistics industry practitioners lack of reverse logistics management experience. For the conventional forward logistics, business usually has a perfect system of statistical analysis. However, reverse logistics, they found that I do not know where to start. how 
many reverse Logistics? How to get the reverse logistics data? How to manage? IT enterprises also can't deal with these problems clearly, so these problems are often dealt with by hand, resulting in extremely low efficiency.

\section{Analysis on how to develop reverse logistics in e-commerce environment}

\subsection{Business must strengthen attention of reverse logistics}

Enterprise senior management should return full attention to reverse logistics and returns management, Business should strengthen the co-operation with retailers and service providers. Enterprise information management need speed up the pace, so that all the logistics business activities will be finished under the guidance of information system, in order to achieve timely and accurate feedback, analysis, forecast. Business should strengthen the staff's awareness of reverse logistics cost management, make costs reducing from the work of the reverse logistics management extended to all business sectors.

\subsection{Zero return policy for some commodities.}

Many network marketing companies sell the product which value is relatively low, or some one-time consuming goods, then the business and customers will lose much if the return policy is also taken, at this time a zero return is possibile. Business give discounts and Rangli for products, company no longer accept the return through this economic compensation. Businesses achieve zero returns that reducing management costs, consumers to buy their products on the Conditions the products can't be returned before they buy, so this reduced the possible disputes when return.

\subsection{Establish appropriate supporting mechanism of talented people}

Human resources are the source of development reverse logistics which can't be separated from the development of human resources planning mechanism. Human resource of reverse logistics is currently relatively weak, the total amount of small, the average level of education and title is low. It is difficult to adapt the needs of the development of reverse logistics. It is lack of some talents who have modern concept of reverse logistics, who is familiar with the operation of modern reverse logistics, who have the knowledge of this field and related businesses. So measures should be taken timely to plan efficient introducing mechanisms and reserving mechanism to meet the urgent needs of talents

\section{Conclusion}

Reverse Logistics is the e-commerce links which can not be ignored, for end customers, representing the credibility and image of business. Reverse logistics provides a platform for companies to better communicate with customers, The e-commerce environment is a more efficient tool and infrastructure for reverse logistics. With the further development of e-commerce, the reverse logistics will become a huge competitive advantage for e-commerce. Research on reverse logistics, set reverse logistics strategy, improve the reverse logistics system Will be benefit for the healthy development of e-business. China's e-commerce companies need to seriously study the phenomenon of reverse logistics, pay attention to the value of reverse logistics, Build e-commerce reverse logistics system.

\section{References}

Fang Han. (2006). The implementation of the reverse logistics in E-commerce environment. Logistics Science and Technology.

Ping Liu. (2005). E-logistics. Beijing: Publishing House of Electronics Industry.

Jing Zhao \& Xinchun Li. (2007). The management of reverse in E-commerce environment. Business Age. 